RESEARCH PAPER RP1318

Part of Journal of Research of the National Bureau of Standards, Volume 25,

August 1940

\title{
AN AUTOMATIC WEATHER STATION
}

By Harry Diamond and Wilbur S. Hinman, Jr.

\section{ABSTRACT}

An important contribution of radio to the collection of weather data consists in the possibility of utilizing completely automatic stations installed at isolated locations, such as mountain peaks, islands, etc., whereby information on the meteorological factors of interest is automatically transmitted at predetermined intervals. Details are given of a method for the remote indication by radio of measurements of barometric pressure, air temperature, relative humidity, wind direction and velocity, rainfall, and other meteorological factors. The method was developed to meet requirements formulated by the Aerological Division, Bureau of Aeronautics, Navy Department, the work being done for that Service.

The method retains the operating principles of the audio-modulation type radio sonde but, because of the use of much lower audio frequencies $(0.15$ to 3.0 cycles per second), affords important simplifications in the transmitting and receiving equipment. The low frequencies allow mechanical keying of a conventional radio telegraph transmitter, thereby avoiding the need for complicated modulating equipment. At the receiving end, the frequency measuring and recording functions are carried out by simple electric counters or by manual counting, which eliminate the expensive electronic-frequency meter and recording microammeter used at radio-sonde ground stations.

An experimental installation set up at the Naval Air Station, Anacostia, D. C., using this method, is described and measurements for a 30-day period are analyzed.

\section{CONTENTS}

I. Introduction

II. The method of remote indication

1. The modulating system

2. Resistors varied mechanically by measuring instruments.... 136

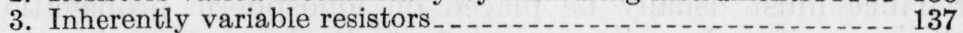

4. Direct keying by cup anemometer.................. 140

III. The control system

1. Automatic rotary switch . .

(a) Homing action . . .

(b) Coding contacts ............ 141

(c) Observation contacts

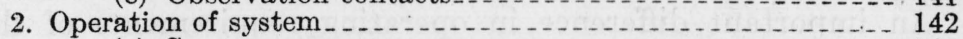

(a) Sequence cam

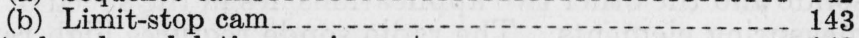

3. Control and modulating equipment

IV. The complete station

1. Electric-circuit arrangement.

2. Experimental equipment $\ldots \ldots$

3. Considerations of radio transmitter power and operating fre-

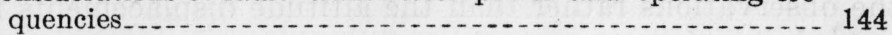

V. The receiving system

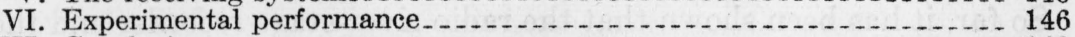

VII. Conclusion _. $\ldots \ldots \ldots \ldots$

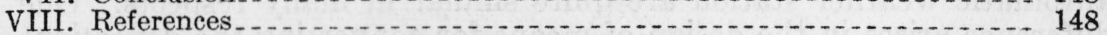




\section{INTRODUCTION}

The development of methods for the remote indication of meteorological measuring instruments has received the attention of experimenters for many years. In recent years, experimental work has been focused on modifying the methods already devised for wire lines to accommodate their use with radio and on the development of methods more adaptable to radio technique. Examples of important applications of radio telemetering in meteorology are: the radio sonde, the radio river-stage recordcr, and the automatic weather station. The radio sonde on the one hand, and the other two applications on the other hand, present sharply different operating problems. It is of interest to consider these differences briefly from the point of view of cost and performance requirements.

In the radio-sonde application, it is important that the cost of the balloon instrument be kept small since it is used but once, but considerable leeway is possible in the cost of the ground-station receiving and recording equipment. Here the emphasis is on performance and speed of operation rather than on cost. The justification lies in the need for rapid evaluation of a large number of observations so that the observed data may be available in time for making scheduled forecasts.

The radio river-stage recorder and the automatic weather station differ from the radio sonde in these respects. The major cost of the system is represented in the transmitting installation, because this end of the system must be capable of unattended operation for periods up to 3 months and the required accuracy of measurement is somewhat greater than for the radio sonde. Since only a few measurements are made during each operating sequence, the need for low observation time and rapid evaluation at the receiving end is reduced, so that, in some instances, manual observations are sufficient. This renders possible a material decrease in the cost of the receiving station. The change in the ratio of cost of the transmitting to the receiving station (as compared to the radio sonde) is further accentuated by the nature of the radio path. The service may be over a great distance, so that reliance must usually be placed on ionospheric propagation. The efficiency of propagation is substantially lower than for the line-ofsight path available in radio-sonde operation, and there is a consequent increase in the transmitter power required. Moreover, for reliable 24-hour operation, more than one operating frequency may be required.

An important difference in operating requirements of the radio sonde and the other two applications lies in the speed of response of the measuring elements. The radio sonde requires high rates of response so that the time for a complete sounding may be kept within practicable limits. The other two applications can tolerate greater lag in response, since such lag merely introduces temporal displacements in the observations rather than the altitude displacements for the radio sonde.

So far, it has been shown that the radio river-stage recorder and the automatic weather station are quite similar in many respects. One difference arises in the design of means for converting the deflections of the measuring devices into characteristics of the emitted radio wave which may be interpreted at the receiving end. The float and pulley 
of the river-stage instrument provide ample power for operating practically any keying or coding mechanism which can be devised, whereas the delicate instruments of a weather station afford very little direct power for such use. This difference justifies the use of substantially different telemetering methods for the two applications $[1,2] .^{1}$

\section{THE METHOD OF REMOTE INDICATION}

In an automatic weather station, measurements may be required of barometric pressure, ambient temperature and relative humidity, wind velocity and direction, rainfall, visibility, ceiling height, and probably other factors. It is evident that each of the measurements noted may be indicated at a remote point by radio by converting the deflection of the measuring instrument into a corresponding variation of electrical resistance and translating the resistance variation into the variation of a modulation frequency on the emitted carrier wave. This is the method used in the audio-modulation type radio sonde [3].

\section{THE MODULATING SYSTEM}

The translation of resistance variations into corresponding variations of modulating frequency is accomplished by means of a trigger-type modulating oscillator. The circuit arrangement is shown in figure 1 .

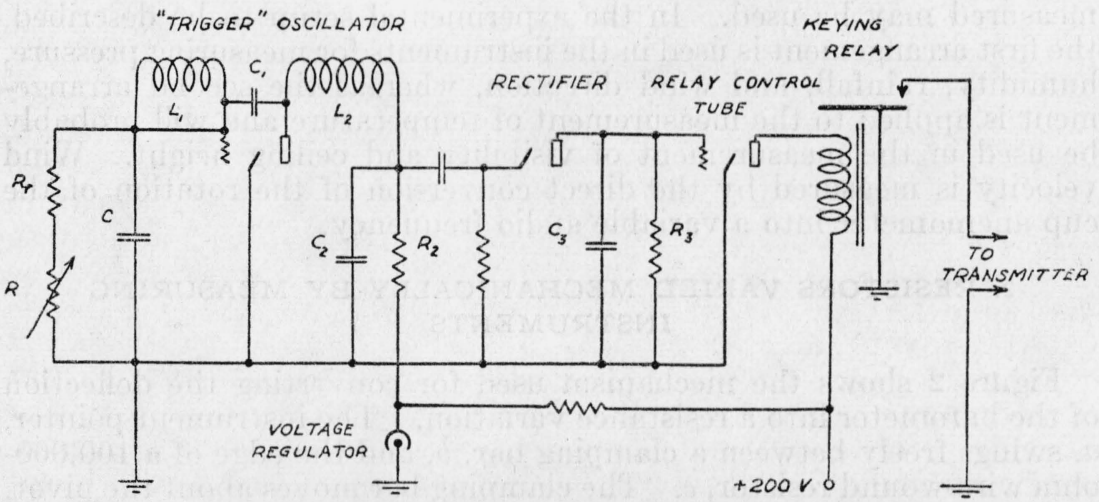

FIGURE 1.-Electric-circuit arrangement of system for keying radio transmitter.

The oscillatory circuit, $L_{1} C_{1} L_{2}$, is tuned to a frequency of about $1 \mathrm{Mc} / \mathrm{s}$. The 1-Mc oscillations are interrupted at an audio rate determined by the time constant of the resistance-capacitance combination, $R_{f} R C$. Here $R$ is the variable resistor (generally in series with a limiting reference resistor, $R_{f}$, of about $40,000 \mathrm{ohms}$ ) and $C$ is a stable condenser of about $8 \mu \mathrm{f}$ capacitance. For the range of resistance values used in the automatic weather station, the range of modulation frequencies extends from about 0.15 to about $3.0 \mathrm{c} / \mathrm{s}$. Because of the low frequencies used, it is convenient to speak of them as so many pulses per second.

The output of the modulating oscillator is coupled to a half-wave rectifier which, in turn, applies negative voltage to the input of the

\footnotetext{
${ }^{1}$ Figures in brackets refer to the literature references at the end of this paper.
} 
relay control tube. The smoothing filter, $R_{2} C_{2}$, in the plate circuit of the modulating oscillator, converts the groups of $1-\mathrm{Mc}$ oscillations into corresponding audio-frequency pulses. After rectification, these appear as negative pulses on the grid of the relay control tube; their duration is controlled by the time constant of the network, $R_{3} C_{3}$. The relay is normally in the actuated position; the armature is released upon application of the negative pulses to the grid of the relay control tube and remains open so long as the grid bias is sufficient to keep the current through the relay coil below the "pull-in" value. The back contact of the relay may thus be used for keying any conventional radiotelegraph transmitter; there is seen to be no limitation on the power output of the transmitter.

The use of low modulation frequencies ( 0.15 to 3.0 pulses per second) not only provides for simple modulation of a radio transmitter but also affords considerable simplification in the equipment for measuring and recording the modulation frequencies at the receiving station. Manual observations may be made simply by counting the number of pulses received in a given time interval (20 to 40 seconds). A stop watch and headphones are sufficient for the purpose. Recorded observations may be obtained with a simple tape recorder which provides distinguishable tenth counts and a timing mark on the tape.

As in the radio sonde, the resistor, $R$, in the grid circuit of the modulating oscillator may be varied mechanically by the instrument deflection, or resistors which vary inherently in response to the factors measured may be used. In the experimental setup to be described, the first arrangement is used in the instruments for measuring pressure, humidity, rainfall, and wind direction, whereas the second arrangement is applied to the measurement of temperature and will probably be used in the measurement of visibility and ceiling height. Wind velocity is measured by the direct conversion of the rotation of the cup anemometer into a variable audio frequency.

\section{RESISTORS VARIED MECHANICALLY BY MEASURING INSTRUMENTS}

Figure 2 shows the mechanism used for converting the deflection of the barometer into a resistance variation. The instrument pointer, $a$, swings freely between a clamping bar, $b$, and the edge of a 100,000ohm wire-wound resistor, $c$. The clamping bar moves about the pivot, $d$, and serves to clamp the pointer against the resistor when the relay, $e$, is actuated. The variable resistance is formed between one end of the resistor and the instrument pointer which constitutes the variable contact point. The field coil of the relay is excited when an observation of pressure is required. (The timing and switching arrangement for starting the automatic weather station and for selecting the observations from the several instruments in the desired sequence will be described later in the paper.) Details of the linkage system for operating the pointer, $a$, from the evacuated bellows will be evident from a study of the two views of figure 2 .

It will be evident that this general scheme for converting the deflection of an instrument pointer into a proportional value of resistance may be applied to any instrument no matter how delicate. An obvious advantage lies in the fact that the pointer reaches its reading position without friction introduced by the electric contact. 


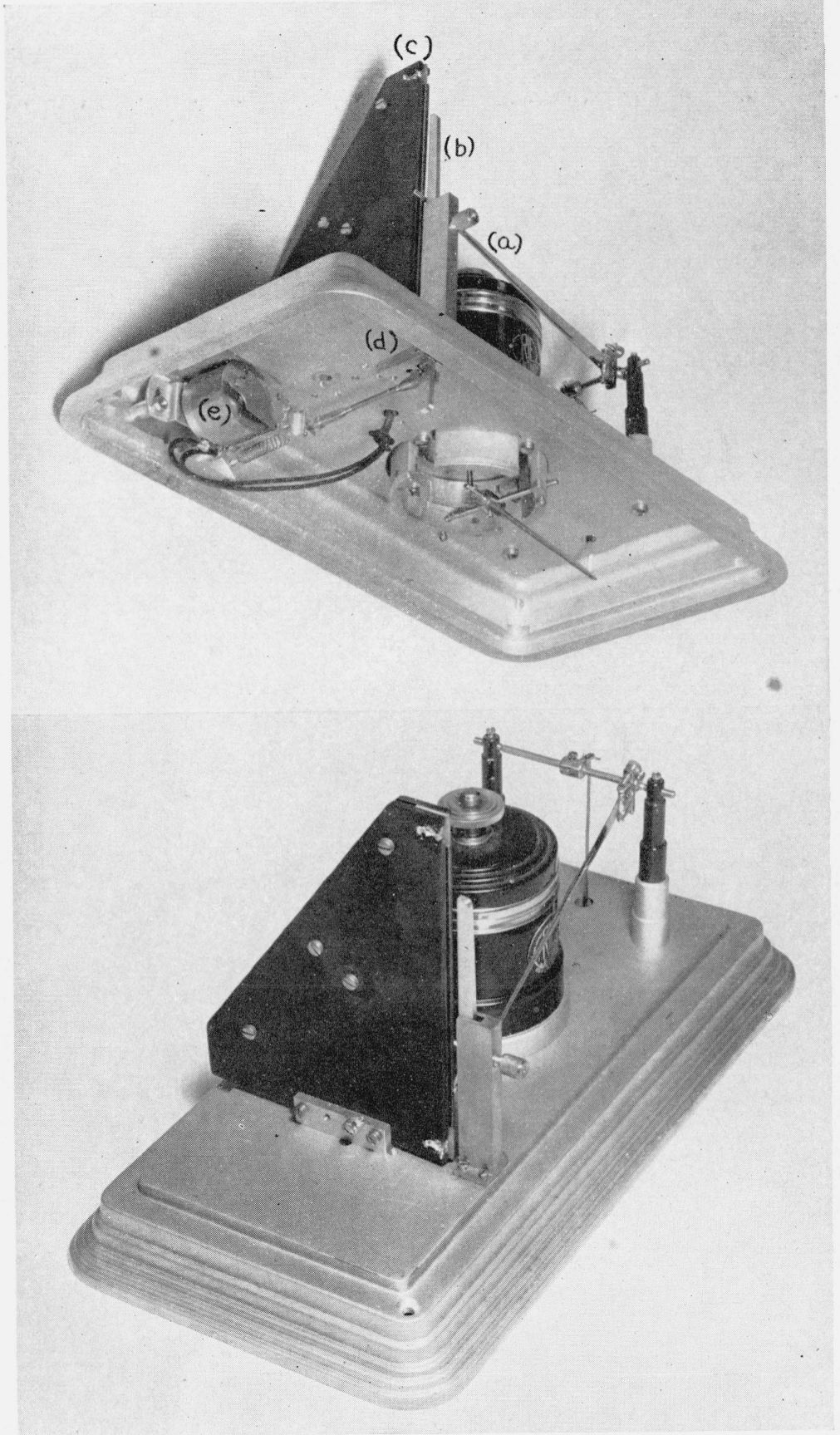

FIGURE 2.-Mechanical arrangement for converting deflection of barometer into a resistance variation. 


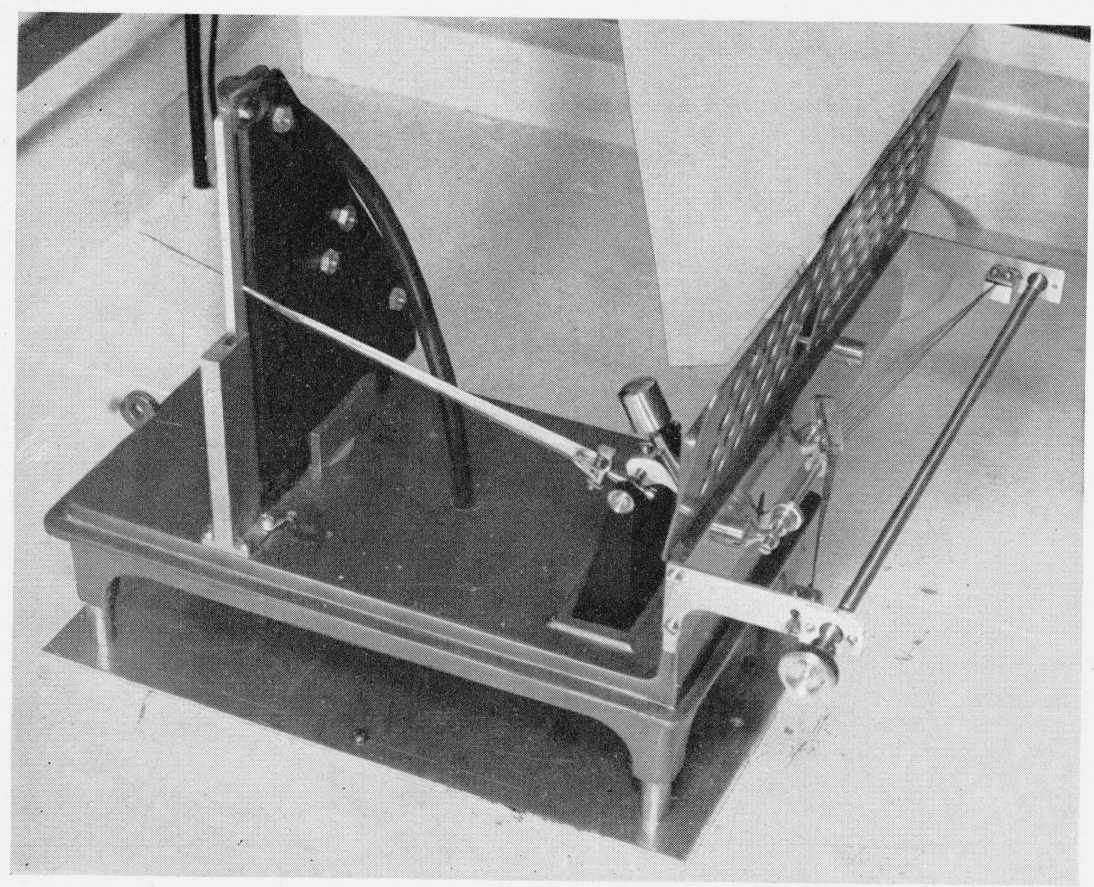

FIGURE 3.-Hair hygrometer controlling a variable resistor. 


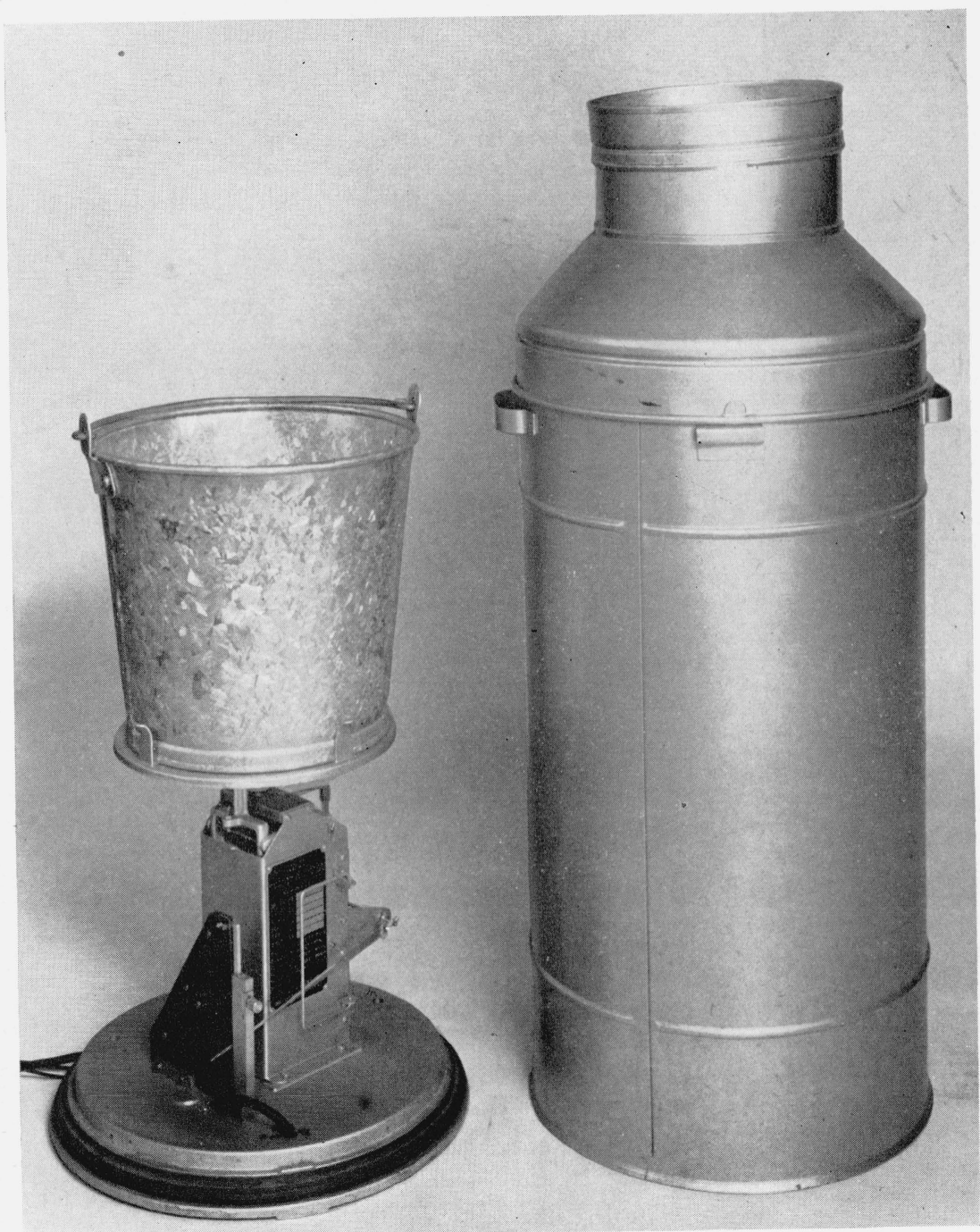

FIGURE 4.-Weighing-type rain gage controlling a variable resistor. 


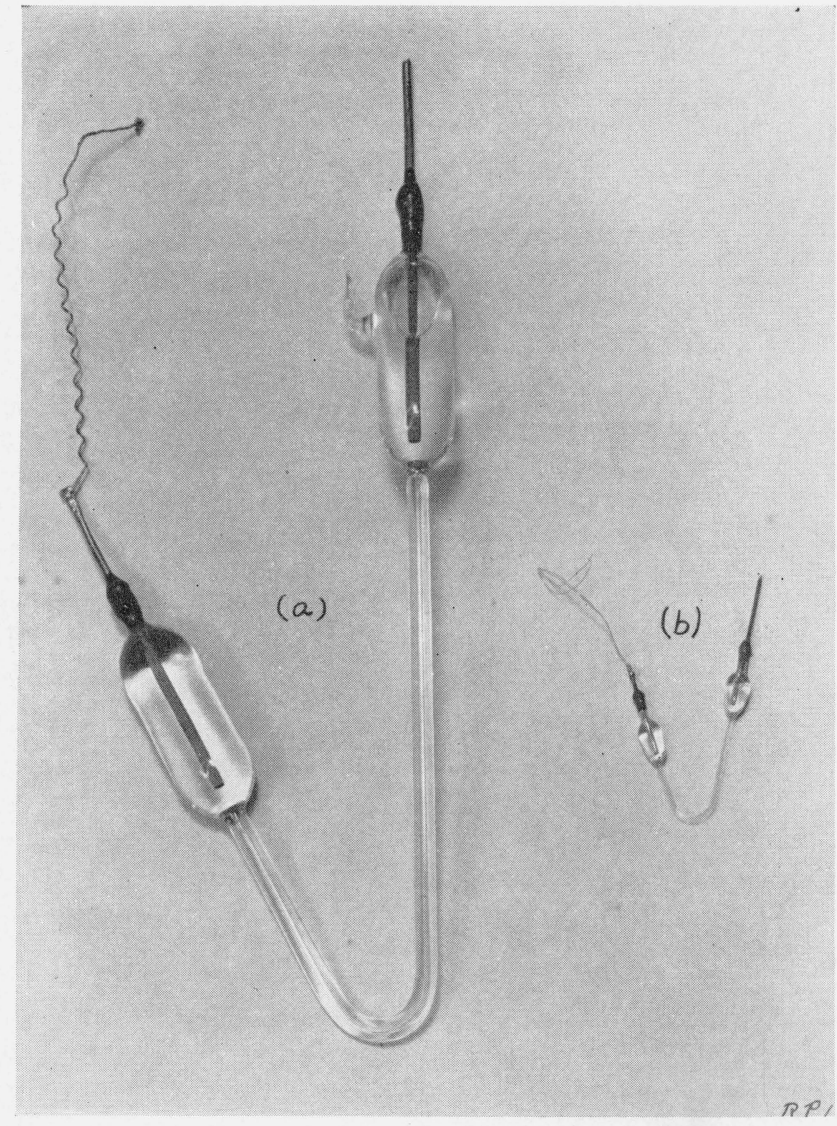

FIGURE 5.-Inherently variable resistor responsive to ambient temperature. $a$, Unit used in automatic weather station; $b$, unit used in audio-modulation type radio sonde. 
The application of this scheme to the hair hygrometer and to the weighing-type rain gage will be evident from figures 3 and 4 , respectively.

The conversion of the position of a wind vane into a corresponding value of resistance is most readily accomplished through the use of a series of different fixed resistors which are switched into circuit as the wind vane passes through its principal positions. The standard wind vane used in the experimental setup has eight equally spaced switching positions; hence, eight different resistors are used. From this it would appear that only wind directions corresponding to the eight principal compass points are indicated. However, it is possible to provide effective indication for eight additional points intermediate to the principal points by taking advantage of the fact that the wind vane oscillates considerably about its average position when the wind velocity exceeds a few knots per hour. The cams for switching in the resistors cover only an are of just under 45 degrees (instead of 60 degrees in the standard wind vane), so that if the wind direction corresponds to a principal position only one resistor is connected into circuit. However, if the wind direction is intermediate to two principal directions, the two corresponding resistors will be switched successively into circuit by the oscillation of the vane, so that the number of pulses counted in a convenient time interval (say, 15 seconds) will represent an average value and thus indicate an intermediate direction.

\section{INHERENTLY VARIABLE RESISTORS}

The inherently variable resistor used for measuring air temperature is shown in figure 5, at $a$. It is similar in all respects except size to the electrolytic thermometer, $b$, used in the audio-modulation type radio sonde. It consists of a glass capillary tube filled with an electrolyte having a high temperature coefficient of electrical resistance and provided with terminals so that it may be used as a resistor whose value varies in accordance with the ambient temperature. The capillary bore is only $0.75 \mathrm{~mm}$ in diameter; the wall thickness (although contributing to lag in response) adds materially to the mechanical sturdiness of the device. The large end wells and heavy copper terminals provide for almost indefinite life of the device under the conditions of intermittent service contemplated for the automatic weather station. For the length of capillary shown $(22 \mathrm{~cm})$, the device has a resistance of $40,000 \mathrm{ohms}$ at $+40^{\circ} \mathrm{C}$; at $-40^{\circ} \mathrm{C}$. its resistance increases to $480,000 \mathrm{ohms}$. The time-lag constant [4] of the device in gently moving air $(25 \mathrm{~m} / \mathrm{min})$ is $2 \mathrm{~min}$ compared to $20 \mathrm{sec}$ for the radio-sonde tube with the same ventilation. As previously indicated, the increased lag in response is of little importance; temperature changes of the order of 0.5 degree per minute are not frequent, and even in such cases the error introduced would be only 1 degree.

It is evident that the use of the electric hygrometer [5] for measuring relative humidity is feasible. An experimental unit was incorporated in the setup to be described, but final design details have not been completed.

Graph $a$ of figure 6 shows the variation of modulation frequency with resistance for the modulating oscillator of figure 1 . The abscis- 

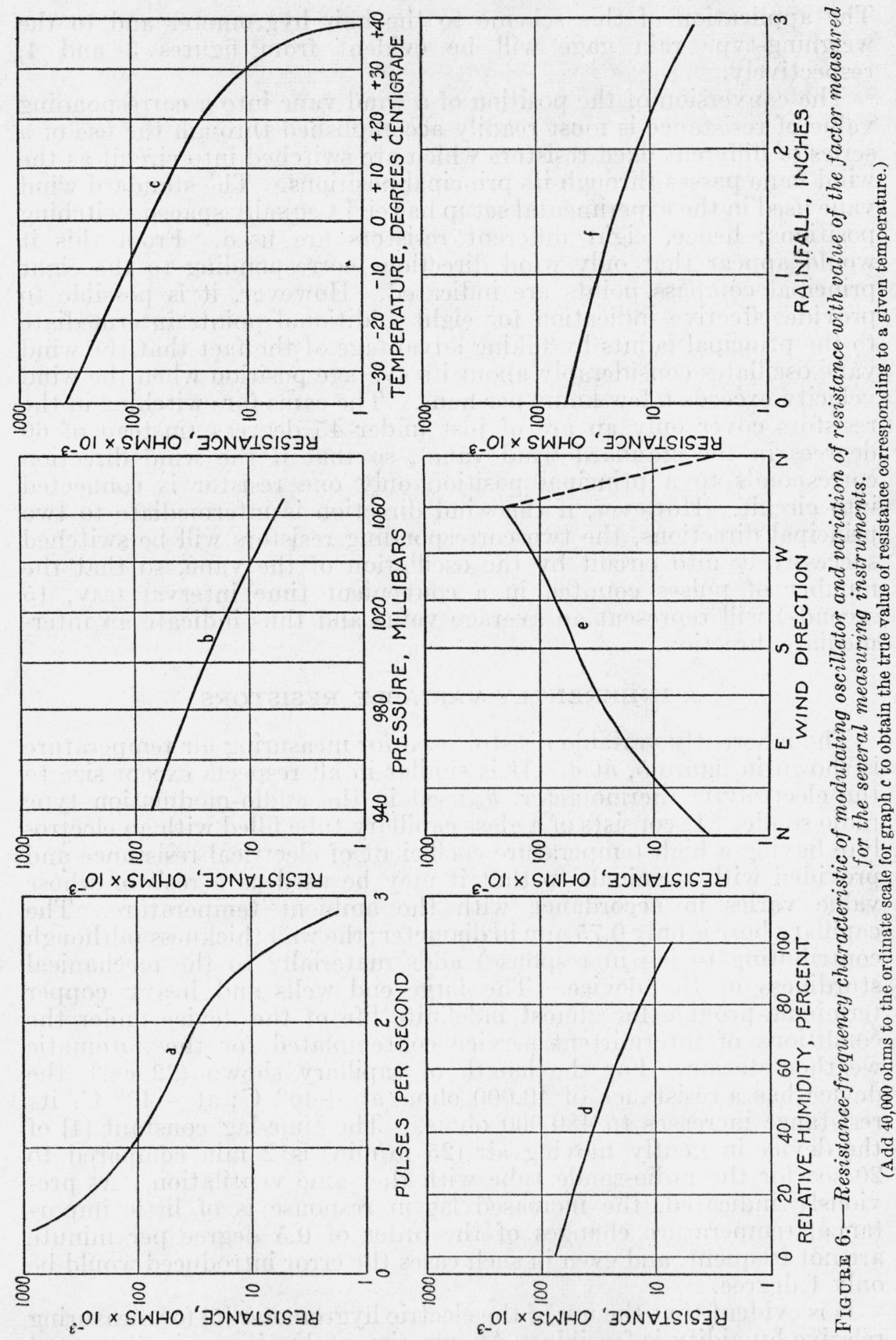

sas represent the generated audio frequencies in pulses per second while the ordinates correspond to the values of the resistance $R$. Graphs, $b, c, d, e$, and $f$ of figure 6 show the range of variation of resistance obtained corresponding to the indicating ranges of the 
pressure, temperature, humidity, wind direction, and rainfall instruments respectively.

When any one of the several instrument resistors is connected as $R$ of figure 1, the variation of the pulses per second as a function of the meteorological factor being measured is as shown by the graphs of
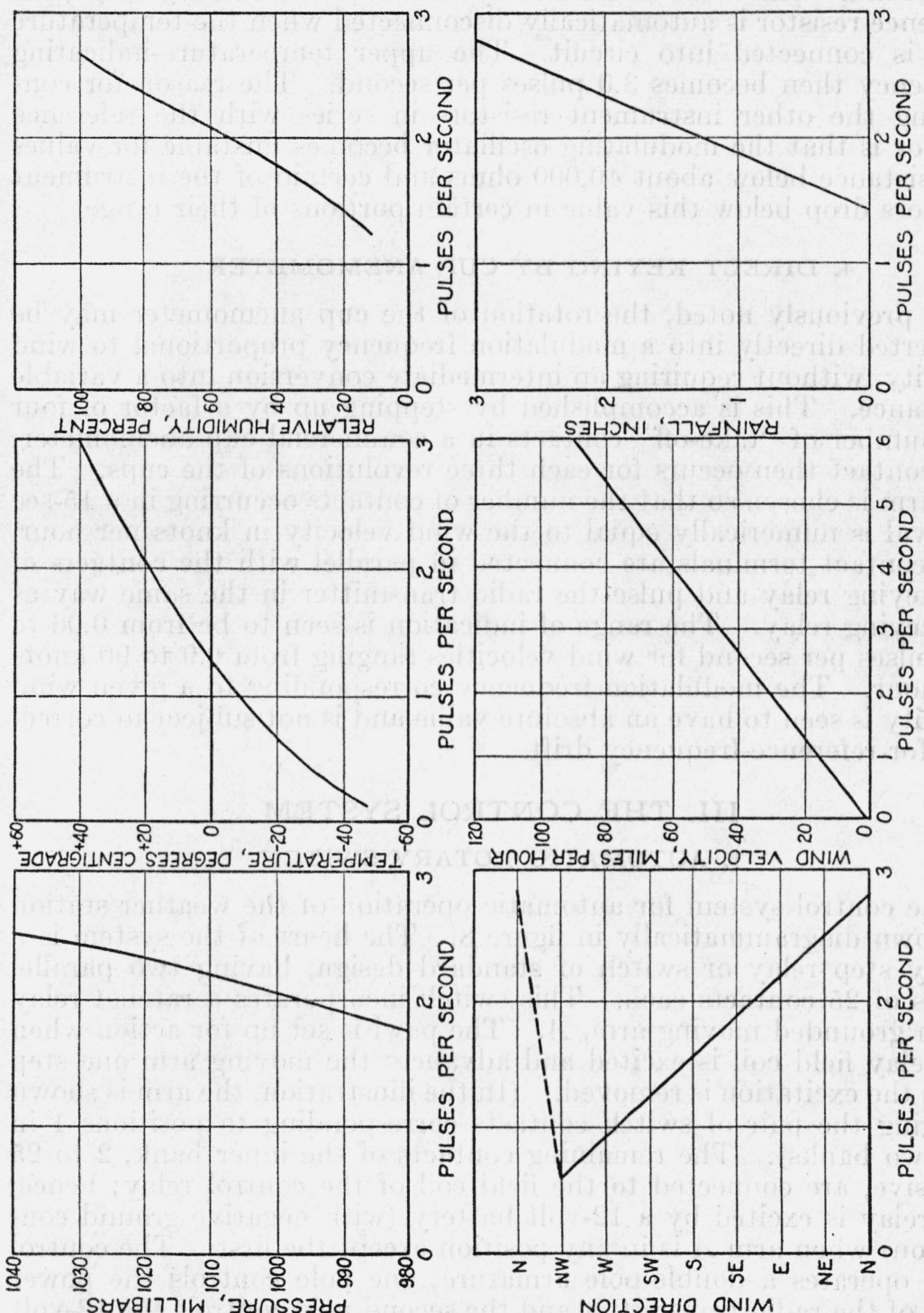

ป⿱艹

figure 7. These are based on a reference frequency of 3.0 pulses per second (that is, when $R=0$ and only the reference resistor of 40,000 ohms remains in circuit). When the reference frequency deviates from exactly 3.0 pulses per second, the frequencies corresponding to various values of $R$ may be corrected proportionally. Hence, the 
graphs of figure 7 constitute a calibration for the automatic weather station.

For the temperature tube, connection of the device in series with the reference resistor would result in a value of resistance at $+40^{\circ} \mathrm{C}$ of $80,000 \mathrm{ohms}$ and a corresponding upper-frequency limit of 1.7 pulses per second. Since this would unduly restrict the indicating range, the reference resistor is automatically disconnected when the temperature tube is connected into circuit. The upper temperature-indicating frequency then becomes 3.0 pulses per second. The reason for connecting the other instrument resistors in series with the reference resistor is that the modulating oscillator becomes unstable for values of resistance below about $40,000 \mathrm{ohms}$ and certain of the instrument resistors drop below this value in certain portions of their range.

\section{DIRECT KEYING BY CUP ANEMOMETER}

As previously noted, the rotation of the cup anemometer may be converted directly into a modulation frequency proportional to wind velocity, without requiring an intermediate conversion into a variable resistance. This is accomplished by stepping up by a factor of four the number of "take-off" contacts in a commercial cup anemometer; one contact then occurs for each three revolutions of the cups. The cup arm is chosen so that the number of contacts occurring in a 15 -sec interval is numerically equal to the wind velocity in knots per hour. The contact terminals are connected in parallel with the contacts of the keying relay and pulse the radio transmitter in the same way as the keying relay. The range of indication is seen to be from 0.06 to 6.0 pulses per second for wind velocities ranging from 0.9 to 90 knots per hour. The modulation frequency corresponding to a given wind velocity is seen to have an absolute value and is not subject to correction for reference-frequency drift.

\section{THE CONTROL SYSTEM}

\section{AUTOMATIC ROTARY SWITCH}

The control system for automatic operation of the weather station is shown diagrammatically in figure 8. The heart of the system is a rotary step relay or switch of standard design, having two parallel banks of 25 contacts each. This switch incorporates a ratchet relay and a grounded moving arm, $A$. The pawl is set up for action when the relay field coil is excited and advances the moving arm one step when the excitation is removed. (In the illustration, the arm is shown bridging the pair of switch contacts corresponding to positions 1 in the two banks). The remaining contacts of the inner bank, 2 to 25 inclusive, are connected to the field coil of the control relay; hence, this relay is excited by a 12 -volt battery (with negative ground connection) when arm $A$ is in any position except the first. The control relay operates a double-pole armature; one pole controls the power relay of the radio transmitter and the second pole controls the 12-volt power circuit to a small, constant-speed motor.

\section{(a) HOMING ACTION}

Contacts 19 to 25 , inclusive, of the outer bank of the rotary switch are connected to the armature of the ratchet relay; the armature normally rests against the fixed contact of the ratchet relay, moving 
away from it when the relay is actuated. The net result is to secure "homing" action of the rotary switch once the grounded arm, $A$, reaches position 19 , as will be evident from a study of the connections.

\section{(b) CODING CONTACTS}

The even-numbered contacts, 4 to 16 , inclusive, of the outer bank of the rotary switch are connected to a set of coding circuits which provide the station identification signals and the coded characters $P, T, H, D, V$, and $R$, corresponding, respectively to pressure. temperature, humidity, wind direction, wind velocity, and rainfall,

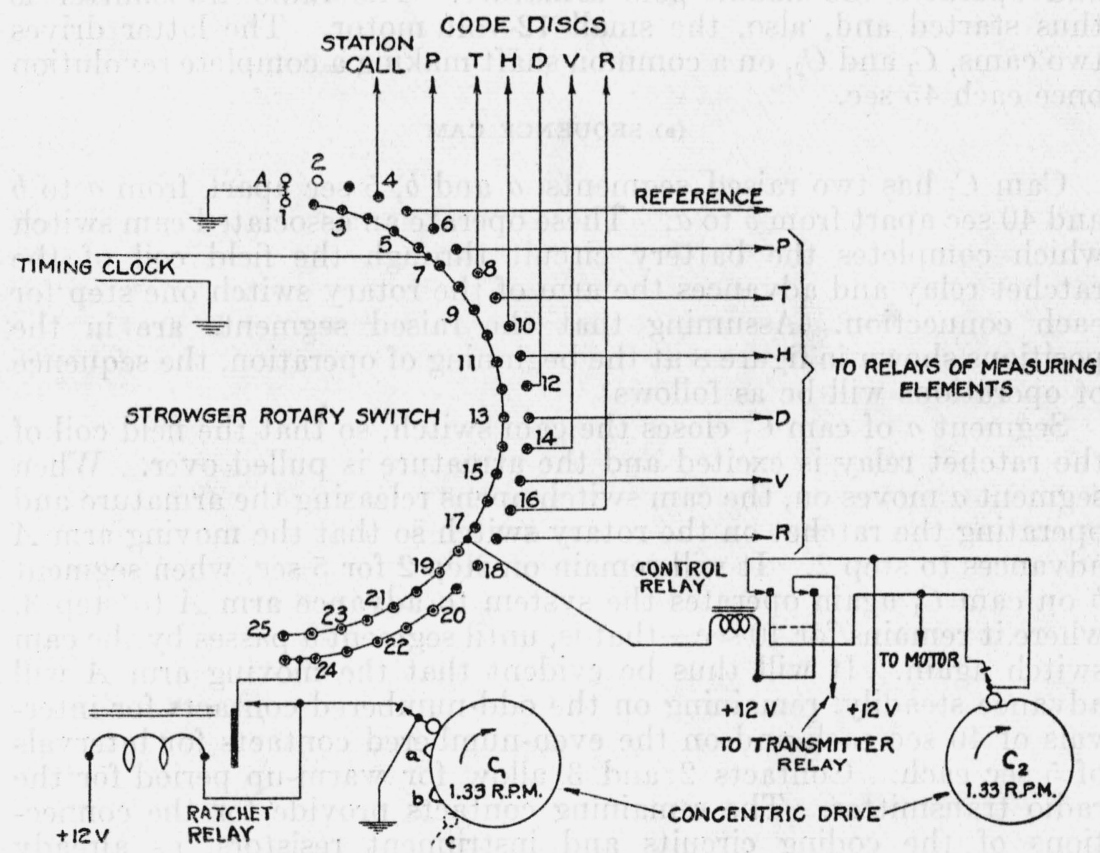

FIGURE 8.-Control system for automatic weather station.

Other code letters corresponding to visibility, ceiling, height, etc., may be added by adding the even-numbered contacts 18,20 , etc., to the coding network. The coding circuits consist of cam-operated switches which are connected in parallel with the telegraph key of the radio transmitter through the grounding of one side by the appropriate even-numbered contacts of the rotary switch.

\section{(C) OBSERVATION CONTACTS}

The odd-numbered contacts 5 to 17 , inclusive, of the outer bank of the rotary switch are connected to relays associated with the measuring elements for connecting the variable resistors, $R$, in the modulating circuit (see fig. 1) and for operating the clamping bars of the pressure, humidity, and rain gage instruments (see figs. 2, 3, and 4). Other measuring-element resistors, such as photoelectric cells for 
measuring visibility, ceiling height, etc., may be added by using contact numbers 19,21 , etc.

Contact 18 of the outer bank is left blank. The reason for this will appear from the following paragraphs.

\section{OPERATION OF SYSTEM}

The operation of the control system may now be outlined. At preset times of day, a clock-operated switch grounds the inner-bank contacts 2 to 25 of the rotary switch and keeps them grounded for approximately $10 \mathrm{~min}$. This excites the field coil of the control relay and operates the double-pole armature. The radio transmitter is thus started and, also, the small 12 -volt motor. The latter drives two cams, $C_{1}$ and $C_{2}$, on a common shaft making a complete revolution once each 45 sec.

\section{(a) SEQUENCE CAM}

Cam $C_{1}$ has two raised segments, $a$ and $b, 5$ sec apart from $a$ to $b$ and 40 sec apart from $b$ to $a$. These operate an associated cam switch which completes the battery circuit through the field coil of the ratchet relay and advances the arm of the rotary switch one step for each connection. Assuming that the raised segments are in the positions shown in figure 8 at the beginning of operation, the sequence of operations will be as follows:

Segment $a$ of cam $C_{1}$ closes the cam switch, so that the field coil of the ratchet relay is excited and the armature is pulled over. When segment $a$ moves on, the cam switch opens releasing the armature and operating the ratchet on the rotary switch so that the moving $\operatorname{arm} A$ advances to step 2. It will remain on step 2 for 5 sec, when segment $b$ on cam $C_{1}$ again operates the system to advance arm $A$ to step 3, where it remains for $40 \mathrm{sec}$ - that is, until segment $a$ passes by the cam switch again. It will thus be evident that the moving arm $A$ will advance steadily, remaining on the odd-numbered contacts for intervals of $40 \mathrm{sec}$ each and on the even-numbered contacts for intervals of 5 sec each. Contacts 2 and 3 allow for warm-up period for the radio transmitter. The remaining contacts provide for the connections of the coding circuits and instrument resistors, as already indicated. The complete sequence of signals from the automatic weather station is shown in table 1. At the end of the observation period corresponding to contact 17, segment $a$ comes by the cam switch, thereby moving arm $A$ to contact 18 . This contact is left blank to allow segment $b$ to pass the cam switch before homing of the rotary switch occurs, so as to leave cam $C_{1}$ in proper position for starting a second sequence of signals.

The homing feature of the rotary switch brings the moving arm to its zero position (contact 1) after the completion of a complete sequence of operation. However, since a complete sequence takes about 6 min and since the clock-switch remains closed for about 10 min, a second sequence of operations automatically begins. Once switch $\operatorname{arm} A$ has moved onto contacts 2, the completion of the second sequence is assured, since, even if the clock-switch opens, the field coil of the control relay remains excited until the rotary switch returns to its zero position. 


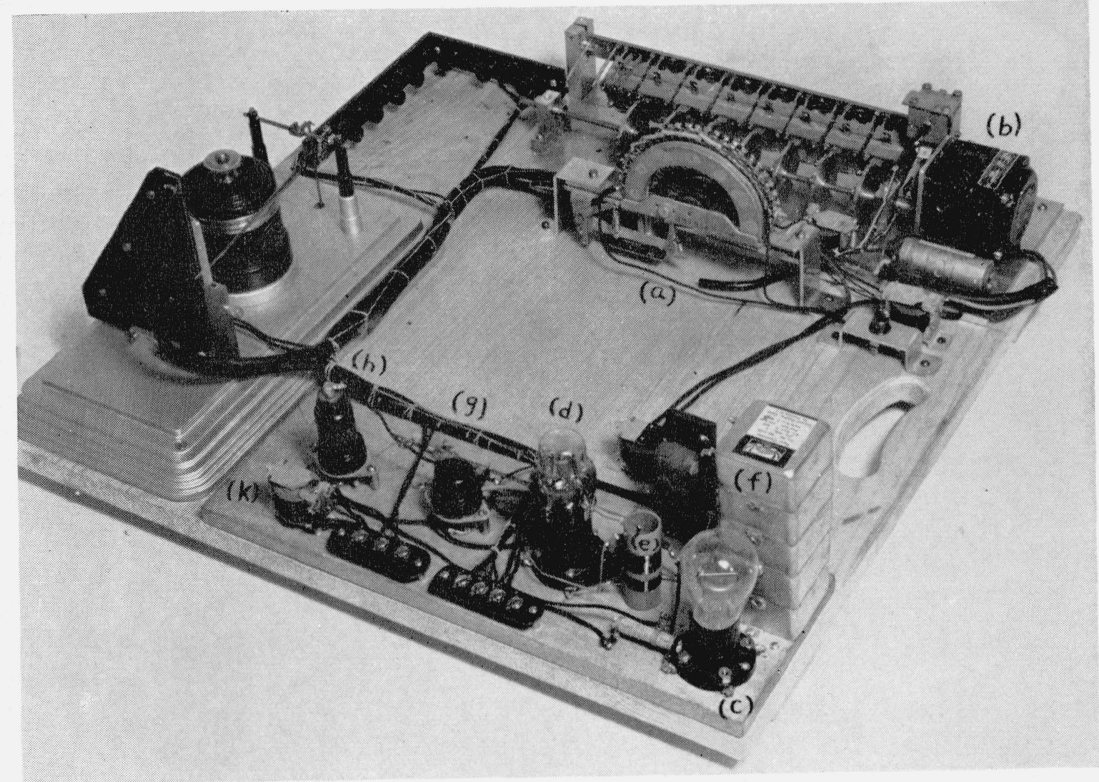

Figure 9.-Control and modulating equipment. 
TABLE 1.-Sequence of signals from automatic weather station. ${ }^{\mathrm{a}}$

\begin{tabular}{|c|c|c|}
\hline $\begin{array}{l}\text { Contact } \\
\text { Number }\end{array}$ & Function & $\begin{array}{l}\text { Time of } \\
\text { duration }\end{array}$ \\
\hline and 3 & 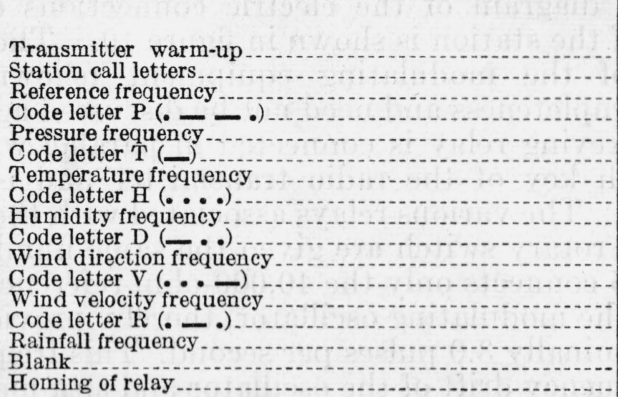 & $\begin{array}{r}\text { Seconds } \\
45 \\
5 \\
40 \\
5 \\
40 \\
5 \\
40 \\
5 \\
40 \\
5 \\
40 \\
5 \\
40 \\
5 \\
40 \\
5 \\
2\end{array}$ \\
\hline
\end{tabular}

s Sequence repeated twice during each operation.

(b) LIMIT-STOP CAM

The function of cam $C_{2}$ may now be considered. After the second sequence of signals has been completed and switch arm $A$ has returned to zero position, it will be observed that cam $C_{1}$ will normally be in a position such that its switch rests at about $c$. The control relay has opened so that, were it not for the cam switch operated by the cam $C_{2}$, the motor would stop. However, this cam switch remains closed except when the depressed section of the cam passes under it. The motor is thus kept running until this point, so that cam $C_{1}$ is automatically brought to the position shown in figure 8 before the motor stops. The system is thus set up properly for the next operating period. The operation of cam $C_{2}$ is normally not important. However, it guards against the possibility of reversal of the time of duration of the code and observation signals in the event of momentary failure of the rotary switch-for example, missing one contact.

\section{CONTROL AND MODULATING EQUIPMENT}

Figure 9 shows the control and modulating equipment used. The control equipment is at the back and the modulating equipment at the front. (For convenience, the barometer is included in this assembly, at the left.) The equipment is seen to be relatively simple. In the control equipment, the rotary switch is shown at $a$, the motor at $b$, and the coding disks and cams $C_{1}$ and $C_{2}$ (with the associated switches) in the bank behind the rotary switch. The two single-pole relays shown to the right rear and right of the rotary switch are used as the control relay in figure 8 . In the modulating equipment, $c$ is a voltage-regulator tube to assure constant plate-voltage supply to the modulating oscillator, $d$, thereby reducing reference-frequency drift; voltage is obtained from the dynamotor which furnishes plate supply to the radio transmitter. The coils $L_{1}$ and $\mathrm{L}_{2}$ used in the modulating oscillator are shown at $e$; and the condenser, $C$, of the time-constant circuit is shown at $f$. The rectifier tube and the relay control tube are shown, respectively, at $g$ and $h$ and the keying relay at $k$. 


\section{THE COMPLETE STATION}

\section{ELECTRIC-CIRCUIT ARRANGEMENT}

A schematic diagram of the electric connections of all the component parts of the station is shown in figure 10. The electric-circuit arrangement of the modulating equipment (shown in fig. 1) is included for completeness and need not be discussed again. It will be seen that the keying relay is connected in parallel with the conventional telegraph key of the radio transmitter and is essentially an automatic key. The various relays associated with the odd-numbered contacts of the rotary switch are given the same numbers as the contacts. Relay 5 connects only the 40,000 -ohm reference resistor in the grid circuit of the modulating oscillator, thereby providing a reference frequency - nominally 3.0 pulses per second. This frequency serves as a check on frequency drift of the oscillator and as a means for correcting the various observations (except wind velocity) for frequency drift. Relays 7,11 , and 17 connect the corresponding instrument resistors in series with the reference resistor; companion relays operate the clamping bars for these instruments. Relay 9 connects in the temperature resistor directly, leaving the reference resistor out of circuit as already noted. The functions of relays 13 and 15 used with the wind-indicating instruments are self-evident. Note that the contact switch in the wind-velocity indicator is connected in parallel with the keying relay and keys the transmitter directly. The code keys (formed by the code disks and associated switches) are similarly connected, operating only when the moving arm of the rotary switch is on the even-numbered contacts. No details of the radio transmitter are given, since it may be any conventional radiotelegraph unit; a tonemodulated transmitter affords the possibility of using simple filters at the receiving station for increasing the signal-to-noise ratio.

\section{EXPERIMENTAL EQUIPMENT}

A photograph of an experimental automatic weather station installed at the Naval Air Station, Anacostia, D. C., is shown in figure 11. The unit has three separate compartments. The top compartment takes the form of the conventional ventilated shelter for housing the temperature- and humidity-measuring elements; it serves also as a support for the wind-measuring instruments. An inside view of this compartment is shown in figure 12. The middle compartment houses the control and modulating unit, already shown in figure 9 . The lower compartment houses the radio transmitter, power supply, and timing clock.

\section{CONSIDERATIONS OF RADIO TRANSMITTER POWER AND OPERATING FREQUENCIES}

There are a number of practical considerations which influence the size of the radio transmitter and the radio frequencies to be used. Since the station is to be installed at isolated locations, the primary power supply is necessarily a storage battery. Although the storage 


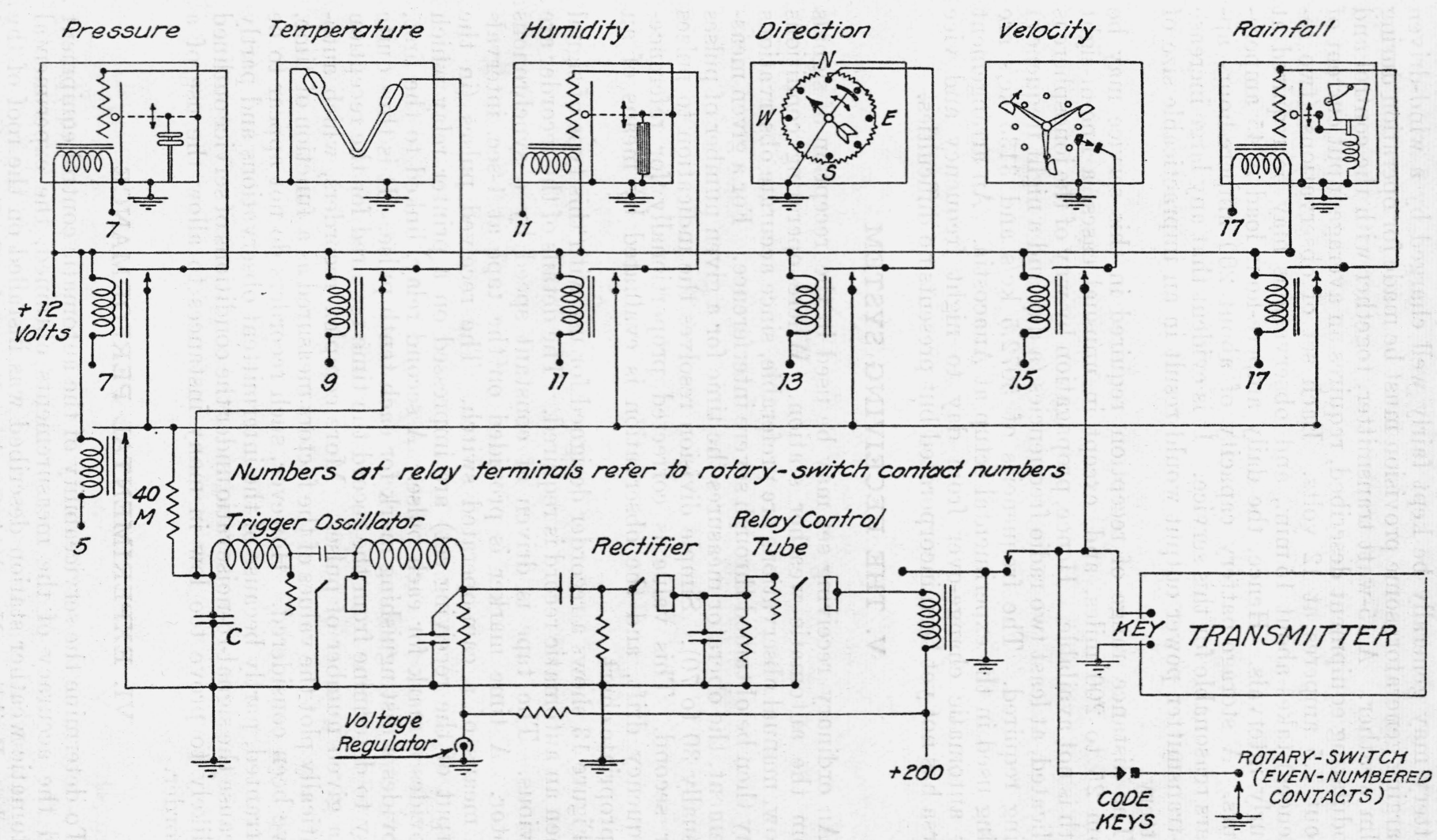

चैं

FIGURE 10.-Circuit arrangement of automatic weather station. 
battery may generally be kept fairly well charged by a wind-driven charging generator, some provision must be made for operation during calm weather. A 15-watt transmitter, together with the control and modulating equipment described, requires an average input current of about 7.5 amperes at 12 volts. Each set of observations (two sequences) takes about $15 \mathrm{~min}$., and observations may be required at hourly intervals. Hence, the daily ampere-hour load is 45 amperehours. A storage-battery capacity of about 200 ampere-hours appears reasonable for this service. It is evident that any large increase in transmitter power output would result in an impracticable size of battery.

The distance range of reception required in this service may be from 25 to 200 miles, and, except in unusual cases, a line-of-sight path is not available. Hence, propagation by way of the ionosphere is indicated, at least two radio frequencies (a day and a night frequency) being required. The frequencies of $5072.5 \mathrm{kc} / \mathrm{s}$ and $3135 \mathrm{kc} / \mathrm{s}$ are being used in the experimental setup at Anacostia. An arrangement for automatic change-over from day to night frequency and vice versa has not yet been incorporated but presents no difficulties.

\section{THE RECEIVING SYSTEM}

An ordinary receiving set may be used in the reception of signals from the automatic weather station. Where operating conditions allow, manual observations are preferable, since accurate observations may then be obtained through severe interference. For a given measurement, the operator measures the time for a given number of pulses (usually 30 to 70 ). Simple division resolves the indication to pulses per second. This value is corrected proportionally for referencefrequency drift, and the observation is evaluated by means of an appropriate chart.

Figure 13 shows a recorder designed for use with this type of signal when an automatic record is required. The details of the recorder are obvious. The tape is driven at constant speed by a synchronous motor. A time marker is provided on the tape at 1-sec. intervals by means of a cam-operated switch. The received pulses (in the output of the receiving set) are impressed on a printer relay which provides a mark for each pulse. A second relay, linked to the first, provides a distinguishing mark for each tenth pulse. It is thus quite easy to determine from the record the time required for the reception of a given number of pulses. More complex recorders, which automatically plot the values of the factors measured as a function of time, have been considered. However, such recorders do not appear to be warranted, partly because of the intermittent observations and partly because the signal-to-noise ratio under the conditions of service outlined is likely to prove too low in many instances to allow the use of a recorder.

\section{EXPERIMENTAL PERFORMANCE}

To determine the serviceability of the automatic control equipment and the accuracy of the measurements obtained, the experimental automatic weather station described was installed on the roof of the Aerology Building, Naval Air Station, Anacostia, D. C., and operated 


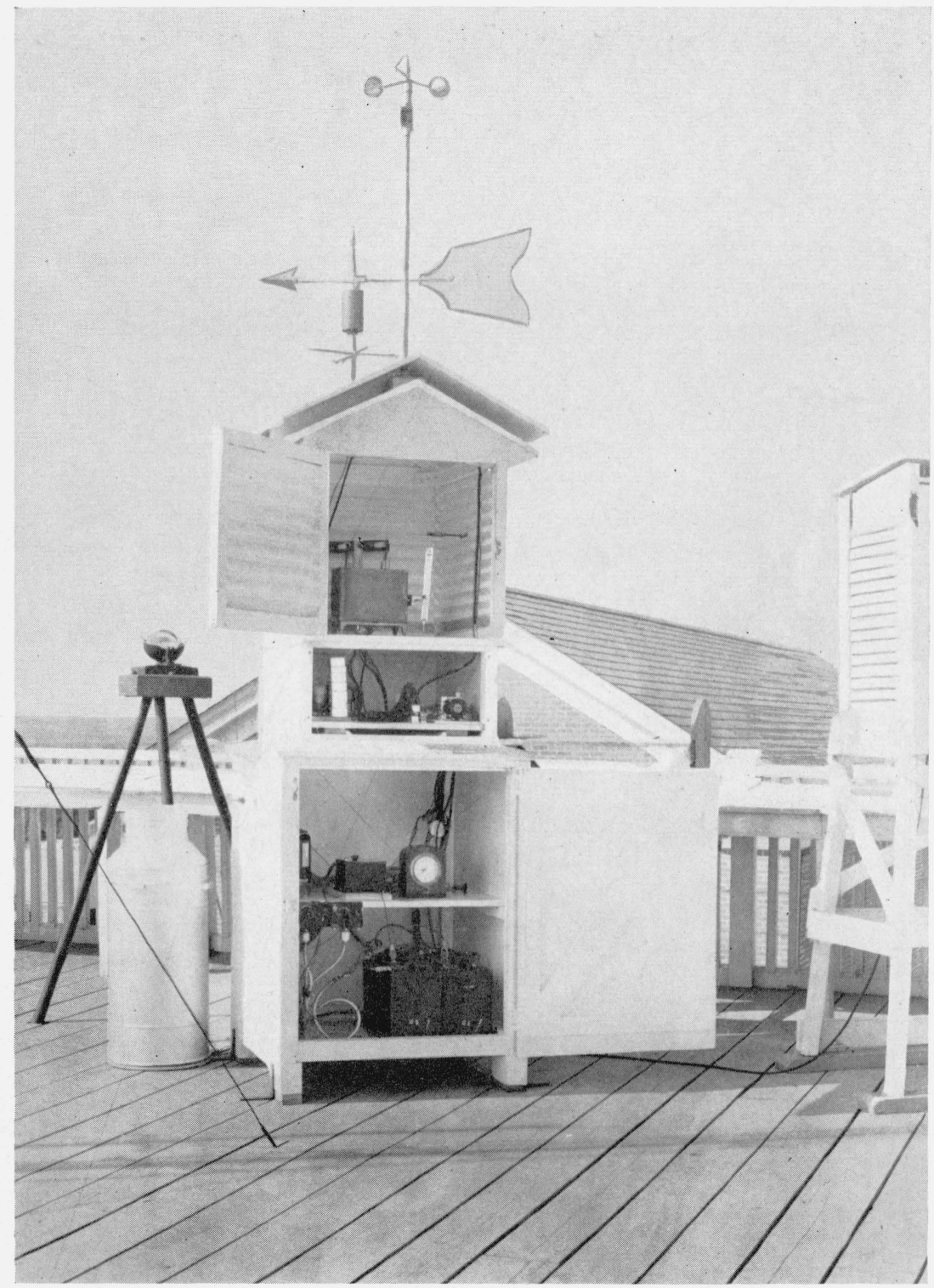

FIgURE 11.-Experimental automatic weather station installed at Naval Air Station, Anacostia, D. C. 


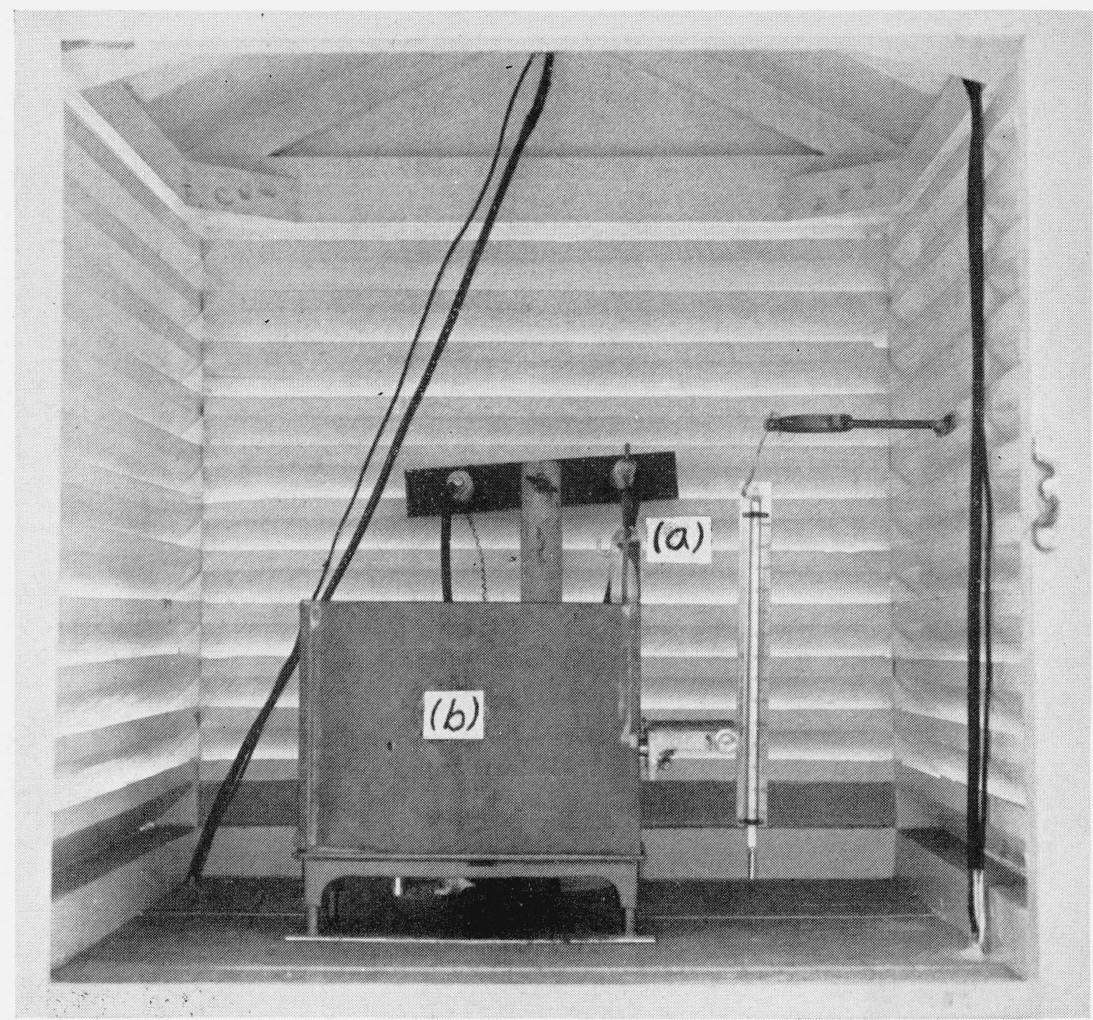

FigURE 12.-View inside ventilated sholter, showing temperature unit at (a) and humidity unit at $(b)$. 


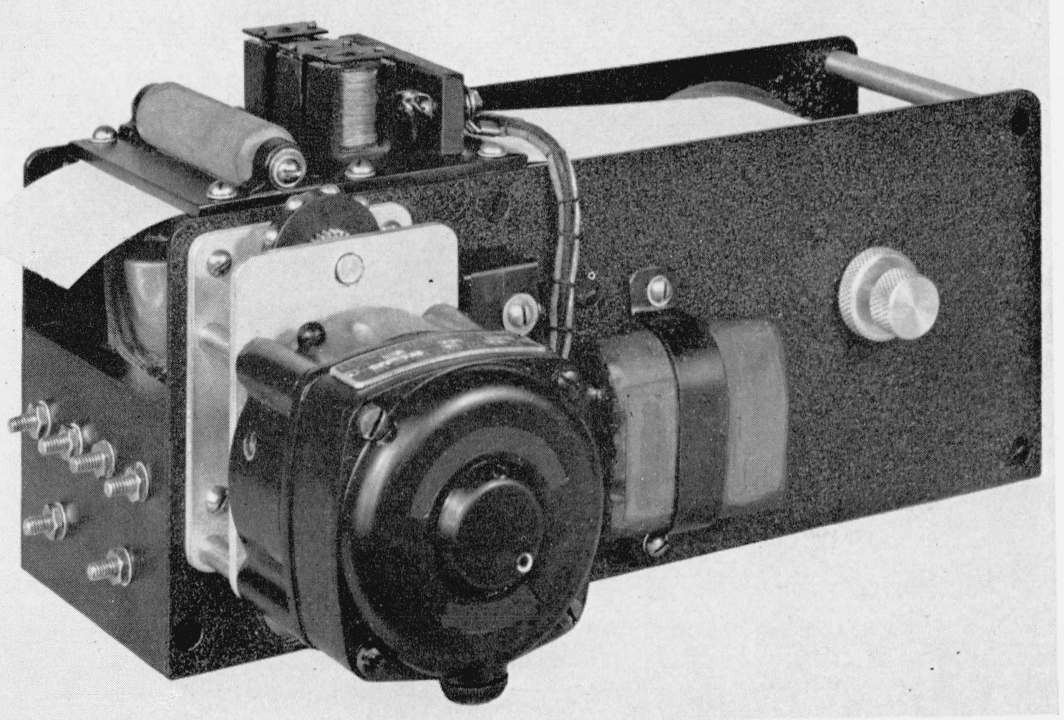

Figure 13.--Tape recorder. 
during April, 1940, three times daily. The operation was entirely automatic except for occasional additional sets of observations for experimental and demonstration purposes. Observations were made by radio at the Bureau laboratories and were compared with routine simultaneous visual observations at the Naval Air Station.

Several minor failures of the equipment occurred during the month. These were all of a mechanical nature and were almost wholly due to the experimental timing and coding mechanism. Satisfactory repairs were made on the spot. No failures were noted which could be attributed to the method or to the measuring elements used. Four different operators, using the manual observation method, took readings on this station and there was no noticeable difference in the accuracies obtained.

The accuracy of the measurements obtained is indicated in figure 14, which summarizes all the measurements for April. Results are
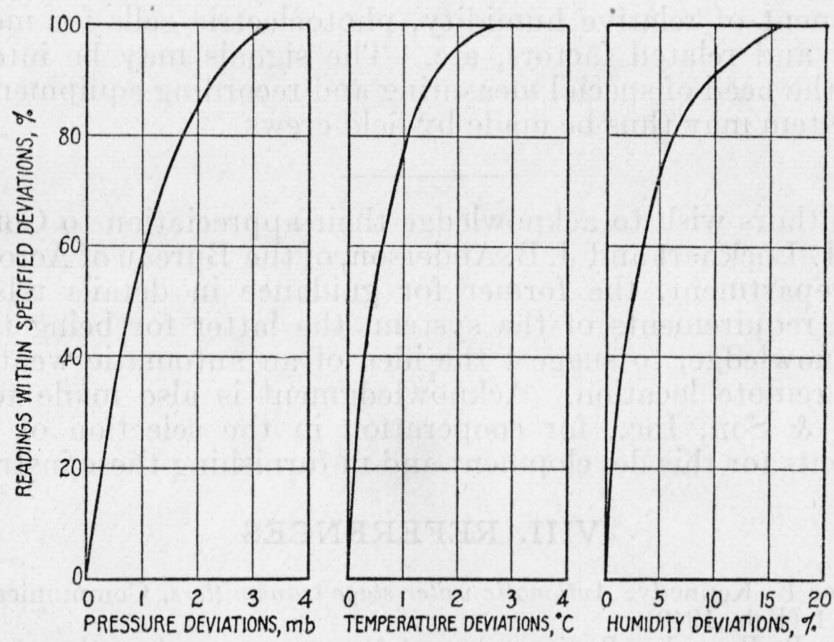

FIGURE 14.-Summary of deviations of observed pressure, temperature and humidity measurements from values as measured with standard weather instruments.

shown only for barometric pressure, temperature, and relative humidity; the error in wind direction was negligible, the error in wind velocity was less than 1 knot per hour, and the number of observations for rainfall proved insufficient for accurate evaluation of error. In figure 14, the abscissas represent deviations between the observed values and the routine measurements at the Naval Air Station with conventional weather instruments; the ordinates plot the percentages of the observed values which agreed within specified deviations. It will be seen that 80 percent of the pressure readings agreed within 1.75 millibars, 80 percent of the temperature readings within 1.1 degrees centigrade, and 80 percent of the humidity readings within 6 percent relative humidity. Some fraction of the errors must be attributed to the comparison instruments and some fraction to personal error; an exact evaluation is not yet available.

It is expected that some improvement in the pressure measurement may be obtained by the use of a barometer having a narrower indicating range or a wider resistance range. Either change would 
result in a much greater range of frequency indication for the range of pressure variation used. (See figs. 6 and 7.) The accuracy of the temperature measurements is believed to be better than indicated in figure 14, a fixed calibration difference of 0.5 degree centigrade between the temperature tube and the comparison thermometer having recently been detected.

\section{CONCLUSION}

In conclusion, it is evident that the system is quite simple. It allows the use of standard radio transmitting and receiving equipment and of standard weather instruments with but slight modification. The modulation and control equipment is special but is more complicated in explanation than in actual design or operation. As described, the system is readily adaptable to the addition of other measuring elements, such as the electric hydrometer for improved measurement of relative humidity, photoelectric cells for measuring visibility and related factors, etc. The signals may be interpreted without the need of special measuring and recording equipment. Use of the system may thus be made by field crews.

The authors wish to acknowledge their appreciation to Commanders W. M. Lockhart and J. B. Anderson, of the Bureau of Aeronautics, Navy Department, the former for guidance in details relating to practical requirements of the system, the latter for being the first, to our knowledge, to suggest the idea of an automatic weather station for remote location. Acknowledgment is also made to Julien P. Friez \& Son, Inc., for cooperation in the selection of weather instruments for this development and in furnishing these instruments.

\section{REFERENCES}

[1] Maurice E. Kennedy, Automatic water stage transmitters, Communications 20, 10-11 (Feb. 1940).

[2] Charles B. Pear, Jr., Radio equipment for an unmanned weather station, Bul. Am. Meteorol. Soc. 21, 107-110 (March 1940).

Lange, Pear, and Dickey, An automatic radio weather station, Bul. Am. Meteorol. Soc. 21, 76-77, (1940).

[3] Harry Diamond, Wilbur S. Hinman, Jr., Francis W. Dunmore, and Evan G. Lapham, Upper-air weather soundings by radio, AIEE Tech. Pap. 40-47 (Dec. 1939).

[4] H. B. Henrickson, Thermometric log of aircraft thermometers, thermographs and barographs, BS J. Research 5, 695-709 (Sept. 1930) RP222.

[5] Francis W. Dunmore, An improved electric hygrometer, J. Research NBS 23, 701-714 (Dec. 1939) RP1265.

Washington, May 28, 1940. 